\title{
A PESQUISA NA FORMAÇÃO DO EDUCADOR AMBIENTAL
}

\author{
Mauro Guimarães ${ }^{1}$; Lana Claudia Fonseca ${ }^{2}$; Lia Maria T. de Oliveira ${ }^{3}$ e Ana Maria \\ Dantas Soares $^{4}$ \\ ${ }^{1}$ Professor do Programa de Pós Graduação em Educação (PPGEduc) e do Instituto Multidisciplinar da \\ UFRRJ.guimamauro@hotmail.com \\ 2, Professora do DTPE/Instituto de Educação/UFRRJ. lanafonseca@uol.com.br. \\ ${ }^{3}$ Professora do DTPE/Instituto de Educação/UFRRJ. liamar@ufrrj.br. \\ ${ }^{4}$ Professora do Programa de Pós Graduação em Educação (PPGEduc), do Programa de Pós Graduação \\ em Educação Agrícola (PPGEA) e do DTPE/Instituto de Educação/UFRRJ. adantas@ufrrj.br.
}

\section{Resumo}

A partir de algumas questões de base, o Grupo de Estudos e Pesquisa em Educação Ambiental, Diversidade e Sustentabilidade (GEPEADS/UFRRJ) procura trabalhar e subsidiar sua reflexão acerca dos processos formativos em educação ambiental e seus efeitos nas práticas escolares. O princípio participativo intrínseco na proposta de realização de uma Educação Ambiental crítica, transformadora e emancipatória, nos leva a relacionar as discussões que vem sendo desenvolvidas, nas últimas duas décadas, sobre o papel da pesquisa na formação e prática docente e que levou a construção da tipologia do professor reflexivo, que pode ser ampliado para a formação do educador reflexivo. Essa reflexão busca superar um sentimento de que prevalece certo "automatismo" na função docente e que vem se consolidando no cotidiano do fazer pedagógico, até mesmo pelas dificuldades encontradas pelo/a professor/a para o seu exercício profissional. Um "automatismo" representado por um fazer não reflexivo, não apto a romper com uma "armadilha paradigmática" e que leva a uma reprodução de uma rotina centrada na transmissão do conteúdo escolar já sistematizado (principalmente pelo conhecimento científico), em que o livro didático acaba assumindo um papel central no processo de ensino-aprendizagem. Portanto apostamos aqui na possibilidade do educador reflexivo que sustentado por princípios participativos, pode gerar no processo educativo a construção de conhecimentos em uma práxis pedagógica emancipatória. Desta assertiva decorre a importante questão sobre a familiarização do/a educador/a em sua formação inicial com a prática de pesquisa, principalmente de caráter participativo.

Palavras-Chave: Educação Ambiental; Pesquisa-ação; Práxis pedagógica.

\section{Introduzindo a discussão}

As questões que pretendemos levantar e trazer à discussão neste artigo se voltam para tentar compreender quais as contribuições da pesquisa com abordagens participativas na formação e prática do/a educador/a, em nosso foco particularmente o ambiental, e as possíveis interfaces entre as propostas de projetos escolares de Educação

\footnotetext{
${ }^{1}$ Doutor em Ciências Sociais. Coordenador do GEPEADS /UFRRJ.

${ }^{2}$ Doutora em Educação. Membro do GEPEADS/UFRRJ.

${ }^{3}$ Doutora em Ciências Sociais. Coordenadora do GEPEADS/UFRRJ.

${ }^{4}$ Doutora em Ciências Sociais. Coordenadora do GEPEADS/UFRRJ. Vice-reitora da UFRRJ.
} 
Ambiental (EA) e as metodologias participativas de construção do conhecimento. A partir de indagações que têm estimulado os trabalhos do Grupo de Estudos e Pesquisas em Educação Ambiental, Diversidade e Sustentabilidade, da Universidade Federal Rural do Rio de Janeiro (GEPEADS/UFRRJ), propomos aprofundar concepções acerca dos processos formativos em Educação Ambiental e seus reflexos nas práticas escolares, tendo como questionamentos que nos acompanham: quais as contribuições da pesquisa com abordagens participativas na formação e prática do educador ambiental? Quais as possíveis interfaces entre as propostas de projetos escolares de Educação Ambiental (EA) e as metodologias participativas de construção do conhecimento? A apropriação do princípio participativo na Educação Ambiental transforma o educador/a em um professor reflexivo? Qual o lugar do conhecimento na escola? O conhecimento escolar se equivale ao conhecimento científico? Na perspectiva interdisciplinar, qual a relação entre o educador/a ambiental e os saberes da escola?

Pensamos que os projetos de Educação Ambiental nas redes de escolas realizarse-ão efetivamente quando conquistarmos uma política educacional, voltada para a formação de professores e a profissionalização docente, garantindo o respeito pela diversidade de iniciativas de atores/sujeitos ${ }^{5}$ que há muito intervêm junto às microestruturas socioculturais na perspectiva do trabalho educativo participativo, devidamente contextualizado. Essa afirmação considera o pressuposto segundo o qual as ações formativas nas instituições da sociedade contemporânea são cada vez mais mediadas por multifacetadas dimensões da sociedade (de gênero, de economia, política, cultura, ambiente, etnia, tecnologia), pois aglutinam a diversidade de pensamentos e ações germinadas nos complexos e interdependentes processos sociais.

Neste sentido, a pesquisa participante numa perspectiva de formação docente assume configurações de um amplo projeto sócio-pedagógico responsável por trabalhar a questão socioambiental de forma interdisciplinar, a partir dos conteúdos culturais

\footnotetext{
${ }^{5}$ Baseando-nos em José Machado Pais, fazemos a distinção entre sujeitos e atores nomeando-os a partir do seguinte entendimento, a saber: para nós sujeitos são aqueles que participam de um projeto dando sentido pessoal ou não, mas dando sentido e sofrendo os impactos das possíveis interações dessa participação, enquanto os atores seriam aqueles que são representantes dos indivíduos sociais em situações coletivas, em entidades de classe, categorias, profissionais, etc. Entretanto, para José M. Pais, ambas as nomeações podem ser concebidas como convenções sociológicas, sendo representadas pela entidade de indivíduo social. Para nosso entendimento o mais importante é que nas escolas acontecem ações participativas entre indivíduos sociais que interagem para modificar o cotidiano, em "situações de interação" politicamente orquestradas e que muitas das vezes passam despercebidas na cotidianidade, mas garantem a não determinação estrutural. Assim o livro de José Machado Pais, Vida Cotidiana: enigmas e revelações. São Paulo: Cortez. 2003 se faz bastante representativo para os nossos estudos.
} 
sistematizados pelos sujeitos na tessitura dos processos sócio-históricos, cultural e de trabalho. Associa-se aqueles conteúdos à realidade dos sujeitos da escola, porque cada um deles apreendem e intervêm nos seus contextos micro sociais dependendo de formas políticas e identitárias específicas de seus grupos, dialeticamente imersos no contexto macro estrutural em que estão inseridos.

\section{Construindo conhecimentos a partir da reflexão e da participação}

A partir da compreensão anteriormente colocada é que nos debruçamos sobre a idéia do conhecimento na escola. Transmissão ou Construção dialógica? Desse dilema, radicado na sociologia, filosofia e na pedagogia (ver Saviani apud Trigueiro Mendes, 1983) é que há pelo menos quase três décadas foi sistematizado o pensamento pedagógico em duas tendências antagônicas da prática educativa escolar e de formação do educador ${ }^{6}$. A transmissão, segundo os traços didáticos que assume, nos permite enquadrá-la numa perspectiva que evidencia uma forma humanista tradicional ou humanista-tecnicista que em termos de formação do/a educador/a ambiental para lidar com uma escola complexa e diversa, ratifica todas as formas socioculturais e políticas dominantes na sociedade. Ao contrário, da idéia de transmissão, elegemos a idéia de conhecimento sendo construído dialogicamente entre os sujeitos e os saberes que os constituem. Os traços pedagógicos favorecem a corrente que inspira e orienta um processo de formação que persevera a inclusão de um conjunto de valores e saberes originários de movimentos socioculturais que potencializam a idéia de um educador reflexivo $^{7}$ e em sintonia com as diferenças e a alteridade. Portanto, o nosso trabalho faz um recorte teórico-conceitual e, também, faz uma opção pedagógica dialógica, onde o conhecimento que se constrói, ao longo da formação e socialização docente, está configurado nas interações de indivíduos e grupos culturais, necessitando da pesquisa referenciada socialmente, de modo que os conteúdos apropriados estejam ressignificados

\footnotetext{
${ }^{6}$ Pensamos que a formação ou a socialização do professor dá-se não somente nas instituições de graduação, mas também de processos interativos em que o educador/indivíduo participa no seu dia a dia de sujeito singular. Pensar a pesquisa na formação considera configurações anteriores e posteriores à licenciatura, que foram subjetivamente significadas por interesses e valores construídos no percurso de uma vida. Não dá para impor uma formação baseada na pesquisa como ferramenta teórico-metodológica se a delimitação temática e os objetos de estudos não estiverem inseridas num campo de significações do sujeito que se forma.

${ }^{7}$ Pretendemos aqui ampliar a idéia de professor para educador reflexivo, para, em coerência com a perspectiva crítica de educação ambiental, enfatizarmos as práticas relacionais desse sujeito que, em suas intervenções pedagógicas sobre a realidade, dilui a separação entre escola e comunidade, educação formal e não formal.
} 
em bases humanas/afetivas/reflexivas na relação respeitosa entre Ser Humano-NaturezaSociedade.

Entretanto, o paradigma científico moderno, ao se estabelecer como hegemônico, a partir do século XVI, enraíza-se nos sistemas educacionais fazendo surgir uma forma diferenciada de compreender o mundo. Apesar de todos os avanços que a ciência nos trouxe cabe uma reflexão crítica sobre as bases em que esta consolidação se deu.

Ao substituir uma visão mais complexa de natureza pela noção cartesiana do Universo-máquina, os seres humanos, apesar dos avanços oriundos desta nova forma de pensar, ficaram impossibilitados de trilhar um caminho de conhecimentos mais abrangentes, que ao serem encarados em sua complexidade, permitissem uma visão totalizante da realidade. O pensamento cartesiano, aliado ao empirismo e ao positivismo acabou fundando, sim, uma visão totalitária e reducionista que é a principal responsável pela fragmentação dicotomizante do pensamento científico moderno, um dos maiores entraves a sua ampliação, principalmente, por não permitir a visão do todo com todas suas inter-relações e interconexões. Não obstante, chega-se a noção de ciência como prática cultural inacabada, alimentada pela própria relação do Ser Humano com a natureza, então esta ciência não dará conta de explicar o todo, nem no pensamento científico moderno e nem no crítico-dialético.

É neste sentido que propomos a formação do educador ambiental, baseada na pesquisa, onde esta deve primordialmente, traçar em que visão de conhecimento a pesquisa se alicerça, visto que o trabalho com educação ambiental exige a ruptura com o paradigma hegemônico.

Esta idéia reflete uma visão de conhecimento na qual entendemos que “(...) o conhecimento tem sempre que ser conhecimento a partir de uma certa posição (...) não há pensamento humano que seja imune às influências ideologizantes de seu contexto social” (BERBER; LUCKMANN, 2001: 22-3).

Na perspectiva de um trabalho de formação que envolva a ruptura com uma lógica cientificista, entendemos que várias vozes devem participar do diálogo, de forma que o mesmo se constitua num ambiente propício para uma formação que envolva, não só aspectos informativos do conhecimento, mas que se constitua num conhecimento que nos forme e nos transforme conjuntamente como sujeitos em formação no coletivo. Nesta direção o trabalho de formação em educação ambiental envolve uma polifonia de conhecimentos, pois em 
(...) um mundo em evolução ao qual pertencemos e do qual participamos e que com certeza nos fala através das fórmulas teóricas da ciência, mas também nos saberes populares, nas artes, tradições, literaturas ou místicas...em suma, por todas as vozes da cultura às quais a ciência não pode doravante ficar surda (CHRETIÉN , 1994: 32)

É neste sentido que nossas reflexões baseiam-se em duas assertivas: o conhecimento trazido por aqueles que participam do processo de aprendizagem é base primordial para o trabalho e todos têm possibilidade de aprender e refletir sobre seu aprendizado. Estas duas colocações, a princípio, simples, trazem em seu bojo uma mudança de lógica, pois ao encararmos que todos possuem conhecimentos e que podem refletir sobre seus conhecimentos e seu processo de aprendizagem, rompemos com a lógica cientificista que privilegia um conhecimento em detrimento de outros.

Por isso, entendemos que a idéia de educador-reflexivo é a que melhor se encaixa em nosso tipo de proposta, pois abriga princípios teórico-metodológicos que discutem a visão de conhecimento, a assunção de que todos possuem conhecimentos válidos e possibilidade de refletir sobre os mesmos e, ainda, de que todos podem produzir conhecimentos, portanto sujeitos pesquisadores.

Esta lógica rompe com a tradição hegemônica do professor-educador como mero "reprodutor" de informações e apresenta a escola, com seus sujeitos pesquisadores em interação com seu meio de vida, em seus diversos níveis, como um espaço legítimo de produção de conhecimentos e de reflexão crítica sobre os mesmos e que este ambiente educativo se realiza no processo de ensino-aprendizagem de pesquisa participativa.

Justifica-se assim o princípio participativo intrínseco na proposta de realização da Educação Ambiental (EA) crítica, pela qual optamos, em que a participação potencializa a contextualização sócio-histórico e cultural do processo educativo em que o meio de vida se faz presente. Isto nos leva a considerar as discussões que vem sendo desenvolvidas, nas últimas duas décadas, que levaram à construção da tipologia do professor reflexivo e/ou pesquisador, em que a pesquisa pode se constituir em um processo formativo e presente na docência.

Entretanto, é importante destacar que a idéia de professor reflexivo não é nova. John Dewey, filósofo da educação, defendeu a importância do pensamento reflexivo, escrevendo sobre o papel da reflexão nos seus livros How we think $(1910,1933)$ e Logic: The theory of inquiry (1938). Segundo ele nós refletimos sobre um conjunto de coisas, no sentido em que pensamos sobre elas, mas o pensamento analítico só tem lugar quando há um problema real a resolver. Em outras palavras, quando reconhecemos um 
problema, um dilema, surge à capacidade para refletir, aceitando-se a incerteza. O pensamento crítico ou reflexivo traz em seu bojo uma avaliação contínua de crenças, de princípios e de hipóteses em face de um conjunto de dados e de possíveis interpretações desses dados.

Nos anos 1970, Stenhouse defendia a idéia de professor-pesquisador, numa ótica de profissionalismo docente que se embasava na pesquisa. Para ele "a idéia é de uma ciência educacional na qual cada classe é um laboratório, cada professor um membro da comunidade científica" (STENHOUSE , 1975, p.142).

Já na década seguinte, Schön (1983), lança a expressão reflective practitioner, com uma grande repercussão para a comunidade educativa, que incorpora a idéia de professor reflexivo, caracterizado como o profissional de ensino que reflete sobre a sua própria prática, em todos os momentos, desde o planejamento, o seu desenvolvimento e, posteriormente a ela, avaliando-a. Apesar das críticas que a ele têm sido feitas, apontando inclusive para a sua superação teórica, não é possível deixar de destacar que deve-se a Schön uma nova visão para a formação docente. Diferentes autores, com perspectivas analíticas também diferenciadas, nas décadas subseqüentes, a partir das idéias fomentadas por Schön, têm apontado os seus limites e as sua possibilidades, destacando-se Henry Giroux (1997), Popkewitz (1994), Contreras (1997) e, mais recentemente, Perrenoud (2002).

No Brasil, Pedro Demo (1994, 2000, 2004 e 2006) tem dirigido vários dos seus trabalhos para a defesa do docente-pesquisador. Segundo ele:

Não se trata de exigir milagres do professor, mas que ele tenha condições necessárias de agir como bom formador. Por isso mesmo, não lhe cabe apenas crítica, mas principalmente apoio, sustentação, consideração. Fenômeno dos mais importantes é aprender a aprender, voltado para a formação permanente. É importante concluir o curso, mas, a rigor, nada se conclui, porque a vida continua e o conhecimento se refaz. Podemos falar de saber pensar, no sentido da habilidade maiêutica de desconstruir e reconstruir o conhecimento indefinidamente, pela vida afora. (...) A escola precisa ser um lugar destacado desta inquietude indócil humana, na qual as pessoas se formam para tomar o destino em suas mãos. Aprender bem e sempre é tudo na vida. Esta indocilidade é a da natureza, que não se cansa de se reinventar em cada novo ser. É uma aventura essencialmente aberta, coisa de seres finitos imbuídos de desejos infinitos. (DEMO, 2006, p.2).

Com os cuidados que se deve ter, sempre que uma temática complexa, possibilitadora de controvérsias ideológico-conceituais como essa vem à tona, contar com as elaborações trazidas por Libâneo (2002), nos permite uma reflexão mais aprofundada, principalmente por chamar a atenção para os reducionismos que podem 
marcar a utilização da terminologia professor/a - reflexivo/a. Ele aponta para a necessidade de vivenciar a atitude reflexiva ultrapassando os limites da sala de aula e a perspectiva de busca de solução para os problemas imediatos. Destaca Libâneo que:

[...] a necessidade de reflexão sobre a prática a partir da apropriação de teorias como marco para as melhorias da prática de ensino, em que o professor é ajudado a compreender seu próprio pensamento e a refletir de modo crítico sobre sua prática e, também, a aprimorar seu modo de agir, seu saber-fazer, internalizando também novos instrumentos de ação. (op. cit., p. 70).

Entendemos que é fundamental pensarmos em um educador-reflexivo, desde que a sua formação e a sua prática se fundamentem, em primeiro lugar, na reflexão sobre o contexto social e as influências deste sobre o locus de trabalho no qual ele atua. As metodologias e práticas deverão propiciar uma dinâmica participativa e, neste sentido, as reflexões de Arroyo (2000) introduzem uma dimensão que não pode ser descurada a afetiva. Segundo ele,

A recuperação do sentido de nosso ofício de mestre não passará por desprezar a função de ensinar; mas reinterpretá-la na tradição mais secular, no ofício de ensinar a ser humanos. Podemos aprender a ler, escrever sozinhos, podemos aprender geografia e a contar sozinhos, porém não aprendemos a ser humanos sem a relação e o convívio com outros humanos que tenham aprendido essa difícil tarefa.

Nos parece que essas reflexões buscam superar um sentimento de que prevalece certo "automatismo" na função docente e que vem se consolidando no cotidiano do fazer pedagógico, até mesmo pelas dificuldades encontradas pelo/a educador/a para o seu exercício profissional. Um "automatismo" representado por um fazer não reflexivo, que leva a uma reprodução de uma rotina centrada na transmissão do conteúdo escolar já sistematizado (principalmente pelo conhecimento científico), em que o livro didático acaba assumindo um papel central no processo de ensino-aprendizagem.

\section{A pesquisa e/na formação de educadores ambientais}

A pesquisa, ancorada por metodologias participativas, pode gerar a construção de um conhecimento, que apesar de em processo de ruptura com uma fazer científico tradicional, vem cada vez mais sendo incorporado pela academia e reconhecido como científico. A pesquisa participante e a pesquisa-ação são consideradas como formas de pesquisa qualitativa. Conforme Minayo (1999:10) as metodologias de pesquisa 
qualitativa são entendidas "como aquelas capazes de incorporar a questão do significado e da intencionalidade como inerentes aos atos, às relações, e às estruturas sociais, sendo essas últimas tomadas tanto no seu advento quanto na sua transformação, como construções humanas significativas.”.

Este é o início de um trabalho que busca romper com o monismo metodológico na formação - tanto inicial quanto continuada - de professores (Lopes, 1999), visto que percebemos que historicamente, esta privilegia a metodologia científica das ciências exatas e naturais e exclui outras formas de construção de conhecimento, propomos que caminhos variados para a produção do saber sejam construídos nesta formação, à medida que se organiza um trabalho de pesquisa que envolve diretamente os professores-educadores como sujeitos/atores do processo.

Sendo assim, se nós educadores ambientais que atuamos nas universidades realizarmos pesquisas de caráter participativo e as utilizarmos como ambiente educativo para a formação de novos educadores ambientais, tanto nas diferentes graduações e pós graduações, assim como levando-as ao espaço escolar, promovendo concomitantemente a pesquisa e a formação continuada de professores/as participantes desse processo, estaremos construindo ambientes propícios para a constituição de educadorespesquisadores. Isso pode garantir uma prática reflexiva desse/a educador/a, o que destaca a importância da aproximação entre universidade e escola, entre outras, para a realização de pesquisas colaborativas (pesquisador/a + professor/a), consolidando assim estas pesquisas como um ambiente educativo.

No entanto há na ortodoxia acadêmica quem discorde ainda do caráter científico das pesquisas menos tradicionais com abordagens participativas. Quanto mais do conhecimento produzido por esses meios e ainda num lócus, como a escola, não reconhecido numa visão tradicionalista, como produtor de conhecimento, o que reflete ainda a força hegemônica de uma visão de conhecimento pautado exclusivamente no conhecimento científico tradicional.

Entretanto, em uma perspectiva crítica de EA (Educação Ambiental), o/a educador/a necessita ser um desvelador/a-desconstrutor/a de paradigmas para estar apto a intervir no processo de transformação da realidade, participando na construção da transição paradigmática para uma nova visão de mundo. Um primeiro passo para esta transição, envolve ampliarmos nossa visão de conhecimento e entendermos a complexidade que envolve esta questão, pois ao assumirmos que a dialogicidade (FREIRE , 1987) é a base para a incorporação de uma perspectiva teórico-metodológica 
participativa, é necessário refletirmos sobre a validade de outras formas de conhecimentos, dentre os quais destacamos aqui o conhecimento escolar e o entendendo como todos aqueles conhecimentos produzidos e que circulam no espaço escolar.

Ao pensarmos sobre isso e informarmos a nossa prática, ousamos realizar uma ruptura com o pensamento que consolida a escola como espaço de reprodução e o professor como repetidor de conhecimentos produzidos por outros. Ao assumirmos que a dialogicidade através de metodologias participativas e pesquisadoras é o caminho teórico-metodológico para a formação de educadores ambientais, estamos assumindo que os professores são profissionais que produzem conhecimento e tem toda a real condição de refletirem criticamente sobre os mesmos.

Tanto a pesquisa participante, quanto a pesquisa-ação tornam-se práticas metodológicas capazes de dar uma nova dinamicidade e organicidade ao trabalho pedagógico de formação-intervenção efetivando a materialização da indissociabilidade do tripé ensino-pesquisa-extensão. Desse modo, as experiências desenvolvidas junto às práticas, transformam-se em material a ser pesquisado e reconfigurado na atividade de ensino, passando a ser o elemento articulador do currículo, o qual se coloca em permanente re-pensar.

A Pesquisa Participante é um método que proporciona ao pesquisador o conhecimento da realidade alvo, nela imerso, como também possibilita integrar, através de uma contínua Ação-Reflexão-Ação da situação definida, os participantespesquisadores, pela conscientização e entendimento voltado para a tomada de decisão com vistas à transformação. A corrente teórica que embasa a Pesquisa Participante é a Filosofia da Práxis, que se volta para a totalidade do ser humano, em sua indissociabilidade da reflexão-ação no conjunto de suas relações sociais (GRAMSCI , citado por SEMERARO , 2005, p.31) e no seu potencial e capacidade de criar e transformar a sua própria história.

$\mathrm{Na}$ pesquisa-ação os pesquisadores desempenham um papel ativo no equacionamento dos problemas encontrados, no acompanhamento e na avaliação das ações desencadeadas em função dos problemas. (THIOLLENT , 2002, p.15).

É nesta perspectiva que as metodologias de investigação e análise qualitativas das questões educacionais apresentam-se como uma importante alternativa pedagógica de mudança através da articulação do processo de investigação/ação no campo formação acadêmica, em especial quando falamos na formação de educadores ambientais. 
Neste contexto, a interdisciplinaridade no âmbito científico e no diálogo dos diferentes saberes, que pode ser viabilizada no processo de pesquisa em um ambiente educativo participativo, se apresenta como uma abordagem de construção de um novo conhecimento, o que a nosso ver caracteriza o educador/a ambiental como um educador-pesquisador, no seu sentido amplo entendido como um/a educador/a crítico com atitude investigativa, aberto a integração de conhecimentos, superando a perspectiva da especialização/especialista e da tendência de querer rejuntar as partes/áreas somente por uma simples justaposição (somatório multidisciplinar). O processo de pesquisa, neste sentido mais amplo aplicado ao ensino-aprendizagem, significa, para nós, possibilitar ao educador/a que o/a habilite para ir além da função de transmissor de conhecimentos já sistematizados por outros; visão que ainda hoje predomina na sociedade sobre a função docente. Ir além passa por uma reflexão crítica (fundamentada teoricamente por uma saber científico) que ao intervir na realidade vivida, constrói o conhecimento significativo (que interage o científico com os demais saberes presentes no cotidiano) para a compreensão e intervenção nesta realidade. Portanto, a práxis pedagógica é construtora de conhecimentos e seus sujeitos (educadores/as), neste sentido, são pesquisadores/as.

Superar a rejeição a construção de conhecimento não acadêmico (pesquisa), passa pela aceitação da validade de outros conhecimentos, mesmo que não cientificamente validados. Isso faz parte da transição paradigmática proposta por uma educação ambiental crítica.

Parece-nos ser esse um resgate necessário da função docente e que a realização de ações educativas de caráter participativo e investigativo no ambiente escolar e que as transpõe, pode contribuir para que os projetos de EA consolidem um novo fazer pedagógico. Numa visão mais geral da formação do educador, concordamos com Nóvoa (2001), quando, ao falar sobre as práticas reflexivas, assim se expressa:

Eu diria que elas não são inerentes à profissão docente, no sentido de serem naturais, mas que elas são inerentes, no sentido em que elas são essenciais para a profissão. E, portanto, tem que se criar um conjunto de condições, um conjunto de regras, um conjunto de lógicas de trabalho e, em particular, e eu insisto neste ponto, criar lógicas de trabalho coletivos dentro das escolas, a partir das quais através da reflexão, através da troca de experiências, através da partilha - seja possível dar origem a uma atitude reflexiva da parte dos professores. Eu disse e julgo que vale a pena insistir nesse ponto. A experiência é muito importante, mas a experiência de cada um só se transforma em conhecimento através desta análise sistemática das práticas. Uma análise que é análise individual, mas que é também coletiva, ou seja, feita com os colegas, nas escolas e em situações de formação. 
Apostamos que a construção de campos de possibilidade de formação se dará mais democraticamente quando houver a interlocução entre as instituições formadoras, os movimentos sociais, a escola e o Estado, visando uma releitura permanente das diretrizes de formação, o que obviamente se dará contrário ou fora da lógica atual da política educacional reformista e reguladora predominante ainda nas instituições formadoras.

As diversas experiências em curso nas universidades e instituições escolares do país apontam para a capacidade auto-gestionária dos educadores, estudantes, militantes e formadores de professores para o enfrentamento das demandas sócio-profissionais, no contexto das sociedades contemporâneas que passam por profundas mudanças sociais, culturais e institucionais. Essas propostas de formação amparam-se na diversidade de relações, experiências, contextos políticos, sociais e culturais instituídos e instituintes, gerando e sendo geradas por uma complexa e interrelacionada rede de significados, representações, simbolismos, percepções, fracassos, conquistas, saberes, racionalidade técnica, ou seja, pensamentos, valores, sentimentos e ações que evidenciam descontinuidades e rupturas nos processos identitários docentes na contemporaneidade.

Desta forma, fica notório, que a elaboração deste trabalho explicita a nossa opção teórica, baseada em autores que entendem a educação e a formação do educador como um processo contínuo, de elaboração e reelaboração de conhecimentos em constantes diálogos epistemológicos, políticos e socioculturais. Essa opção teórica se sustenta em bases pedagógico-sociológicas que aceitam a revisão de posturas em permanente reflexividade (daí a pesquisa), sobre o ser-fazer docente que almeja uma perspectiva identitária crítica acerca da realidade social que circunscreve e medeia a docência de um educador ambiental. Entendemos que a formação para a educação ambiental ocupa lugar estratégico como um espaço/tempo fundante de uma formação de educadores comprometida com a educação escolar, em suas diferentes e complexas dimensões e modalidades que as transpassam.

\section{Referências bibliográficas}

ANFOPE. DocumentoFinal do XII Encontro Nacional da Associação Nacional pela Formação dos Profissionais da Educação. Brasília, 2004.

ARROYO, M. G. Ofício de Mestre: imagens e auto-imagens. Petrópolis: Vozes, 2000.

BRZEZINSKI, I.; GARRIDO, E. Análise dos trabalhos do GT Formação de Professores: o que revelam as pesquisas do período 1992-1999. In: Revista Brasileira de Educação. São Paulo: Editora Autores Associados, nº 18, Set/Out/Nov/Dez. 2001. 
BERGER; Peter; LUCKMANN, Thomas.

A construção social da realidade. Petrópolis: Vozes, 2001.

CHRETIÉN, Claude. A ciência em ação: mitos e limites. Campinas: Papirus, 1994.

CONTRERAS, J. La autonomia del profesorado. Madri: Ed. Morata, 1997.

DEMO, P. Pesquisa e construção do conhecimento. Rio de Janeiro: Tempo Brasileiro, 1994.

Artmed, 2000.

Conhecer e aprender: sabedoria dos limites e desafios. Porto Alegre: Livro, 2004.

Pesquisa participante:saber pensar e intervir juntos. Brasília: Editora Líber

Formação. In: Blog do autor. Março de 2006.

DEWEY, J. (1933). How we think. London: Heath.

(1938). Logic: The theory of inquiry. New York, NY: Holt, Rinehart \& Winston.

FREIRE, Paulo. Pedagogia do Oprimido. São Paulo: Paz e Terra, 1987.

GIROUX, H. Os professores como intelectuais: rumo a uma pedagogia critica da aprendizagem. Porto Alegre: Artes Médicas, 1997.

GUIMARÃES, Mauro. A formação de educadores ambientais. Campinas: Papirus, 2004.

LOPES, Alice Casimiro. Conhecimento escolar: Ciência e Cotidiano. Rio de Janeiro: EDUERJ, 1999.

MORIN, E. Ciência com Consciência. Rio de Janeiro, Bertrand Brasil, 1997.

NÓVOA, A (org.) Os professores e sua formação. Lisboa: Dom Quixote, 1997.

. O professor pesquisador e reflexivo. Entrevista concedida à TVE Brasil,

em 13 de setembro de 2001.

OLIVEIRA, L.M.T. Rumos teóricos para novas leituras e reflexões sobre os processos sócio-culturais na contemporaneidade. UFRRJ/CPDA, 2006. mimeo.

PAIS, J.M. Vida Cotidiana: enigmas e revelações. São Paulo: Cortez. 2003

PEREIRA, J.E. D. As licenciaturas e as novas políticas educacionais para a formação docente. In: Educação\& Sociedade. N.68. Campinas, Dez. de 1989.

SCHÖN, Donald A. The reflective pratitioner. Londres: Temple Smith, 1983.

.La formación de profesionales reflexivos. Hacia un nuevo disefio de la enseñanza y el aprendizaje en las profesiones. Barcelona, 1992.

SEMERARO, G. Filosofia da praxis e (neo) pragmetismo. In: Revista Brasileira de Educação. São Paulo: Editora Autores Associados, nº 29, mai-ago, 2005.

TAMAIO, I. O professor na construção do conceito de natureza: uma experiência de educação ambiental. São Paulo: AnnaBlumme Ed. 2000.

TRIGUEIRO MENDES, D. (org.) Filosofia da Educação Brasileira. Rio de Janeiro: Civilização Brasileira, 1983. 